\title{
Stabilisation of a Segment of Autologous Vascularised Stomach as a Patch for Myocardial Reconstruction with Degradable Magnesium Alloy Scaffolds in a Swine Model
}

\author{
Tobias Schilling ${ }^{1, *} \mathbb{C}$, Michael Bauer ${ }^{2}$, Dagmar Hartung ${ }^{3}$, Gudrun Brandes ${ }^{4} \mathbb{(}$, Igor Tudorache ${ }^{1}$, \\ Serghei Cebotari ${ }^{1}$, Tanja Meyer ${ }^{1}$, Frank Wacker ${ }^{3}$, Axel Haverich ${ }^{1}$ and Thomas Hassel ${ }^{2}$ \\ 1 Department of Cardiothoracic, Transplantation, and Vascular Surgery, Medical School Hannover, \\ 30625 Hannover, Germany; igor.tudorache@med.uni-duesseldorf.de (I.T.); \\ cebotari.serghei@mh-hannover.de (S.C.); t.meyer@medimplant.de (T.M.); \\ Haverich.Axel@mh-hannover.de (A.H.) \\ 2 Institut für Werkstoffkunde (Materials Science), Leibniz Universität Hannover, 30823 Garbsen, Germany; \\ michael.bauer@iav.de (M.B.); hassel@iw.uni-hannover.de (T.H.) \\ 3 Institute for Radiology, Hannover Medical School, Hannover, 30625 Hannover, Germany; \\ hartung.dagmar@mh-hannover.de (D.H.); wacker.frank@mh-hannover.de (F.W.) \\ 4 Institute of Neuroanatomy and Cell Biology in the Center of Anatomy, Medical School Hannover, \\ 30625 Hannover, Germany; brandes.gudrun@mh-hannover.de \\ * Correspondence: schilling.tobias@mh-hannover.de; Tel.: +49-511-5326584
}

Received: 29 April 2020; Accepted: 28 May 2020; Published: 29 May 2020

\begin{abstract}
In patients with severe heart failure, the surgical reconstruction of the damaged myocardium with regenerative biological grafts is an innovative therapeutic option. However, natural patch materials are often too delicate for a full wall repair of the left ventricle. A degradable magnesium scaffold could provide temporary mechanical stability until the sufficient physiological remodeling of such grafts. An autologous vascularised gastric patch was employed for the reconstruction of the left ventricular myocardium in a porcine model. Magnesium alloy (LA63) scaffolds were fixed over the biological patch. The function of the implant was assessed via magnetic resonance imaging. Angiography was carried out to detect a connection between the gastric and coronary vasculature. The explants were examined via $\mu$-computer tomography and light microscopy. All the test animals survived. The prostheses integrated biologically and functionally into the myocardium. No rupture of the prostheses occurred. An anastomosis of the gastric and coronary vasculature had developed. The magnesium scaffolds degraded, on average, to $30.9 \%$ of their original volume. This novel technique responds to the increasing demand for regenerative myocardial grafts. The magnesium scaffolds' biocompatibility and degradation kinetics, as well as their stabilizing effects, indicate their applicability in the surgical treatment of terminal heart failure.
\end{abstract}

Keywords: cardiac surgery; terminal heart failure; regenerative therapy; myocardial prosthesis; magnesium scaffolds; degradation kinetics of magnesium

\section{Introduction}

Impairment of the cardiac pump function due to the damage of myocardial tissue may manifest in severe heart failure. In many cases, the treatment of choice is the surgical reconstruction, in which the damaged areas are resected and the defect is covered with synthetic patch materials such as Dacron $[1,2]$ or biological tissues such as autologous pericardium [3,4]. However, autologous pericardium cannot 
always be obtained in sufficient quantities and the currently available synthetic substitutes have no regenerative potential and do not actively contribute to myocardial contraction.

Innovative biological prostheses for myocardial reconstruction with a potential for physiological remodelling may overcome these limitations [5]. However, many grafts lack sufficient vascularisation, which is a prerequisite for the viability of biological prostheses. In addition to its indispensable viability, the ideal heart muscle replacement should primarily fulfill the general requirements for bioartificial prostheses, such as high immunological compatibility, good integrability into the host tissue, the absence of pathogens, regenerative capacity, lifetime durability, unlimited availability, ease of use, and not least cost-efficient manufacture and storage. Moreover, specific properties such as coherent contractility, sufficient mechanical stability, and low diastolic pressure are also required for consideration in the development of bioartificial myocardial tissue. Therefore, synchronised electrophysiology with a physiological spread of action potentials and refractory periods appropriate to the stimulus conduction of the native tissue is mandatory for the good functional integration of the graft.

Autologous vascularised tissues following a physiological remodelling after transplantation into the myocardium can exhibit specific cardiac features and functions and, therefore, could eventually meet these requirements. In animal tests, the applicability of small intestine tissue for the transmural right ventricular reconstruction of the myocardium was demonstrated [6-8]. As early as one month following transplantation, Tudorache et al. were able to detect evidence of cardiomyocytes in the transplanted small intestine tissue employing a swine model. Thereby, they demonstrated the feasibility of the conversion of heterotopic tissue into a functional myocardial prosthesis [6]. However, due to its reduced wall thickness, the small intestine does not offer sufficient mechanical stability for its use for the reconstruction of the left ventricular myocardium. The high-pressure conditions of the left ventricle could cause a formation of dangerous aneurysms in the grafts, with the risk of life-threatening rupture, thrombus formation, and further impairment of the cardiac pumping function. In the present study, therefore, stomach tissue was employed for the reconstruction of the left ventricular myocardium, since stomach features higher mechanical stability in comparison with the tunica muscularis of the small intestine. However, even a patch of stomach tissue is initially not stable enough to reliably withstand an intracardiac blood pressure of up to $240 \mathrm{~mm}$ of mercury. Thus, the initially delicate stomach tissue could be stabilised temporarily by degradable scaffolds. This concept of transiently supporting vascularised biological grafts by degradable scaffolds would allow for exploiting their essential regenerative potential in a broader spectrum of applications.

We have already demonstrated the epicardial applicability and biocompatibility of degradable structures of magnesium alloy LA63 in a swine model [9]. The degradation kinetics of magnesium structures depend on the alloy composition and geometry. Especially when using other than high-purity magnesium (99.99\%), natural impurities in the alloy can cause galvanic corrosion due to the formation of intermetallic phases. Elements like Fe or Mn, e.g., act as cathodic sites within the alloy. Hence, a confluent coating of the magnesium alloy surface is required to prevent an electrolyte from triggering corrosion within the scaffold. A disadvantageously inhomogenous pitting corrosion can be alleviated or at least delayed by a magnesium fluoride layer. Adding lithium and aluminum to form a magnesium alloy (LA63) further decreases the corrosion rate of the scaffold. Lithium alkalizes the corrosion layer and thereby decelerates the oxidation of the magnesium implants. Aluminum forms a protective oxide layer. Thus, using high-purity magnesium, selecting suitable alloys, shaping stable scaffold geometries, and coating the grafts' surface can be utilized to adjust the degradation rate in order to match the expected in vivo remodelling rate of the vascularised biological stomach tissue. Ideally, the physiological transformation processes that lead to sufficient mechanical stability of the biological graft should take place at precisely the magnesium structure's pace of degradation. The long-term therapeutic goal would be a stable and functionally integrated biological myocardial prosthesis after the complete and biocompatible degradation of the stabilising scaffold. 
Therefore, this pilot study aims to investigate the function, integration, and biocompatibility of a left ventricular full wall myocardial replacement with a patch of autologous vascularised stomach tissue, temporarily stabilised by magnesium alloy LA63 structures coated with magnesium fluoride.

\section{Materials and Methods}

All experiments were carried out in accordance with the European Convention on Animal Welfare and were approved by the licensing authority (Lower Saxony State Office for Consumer Protection and Food Safety (LAVES), Lower Saxony) in accordance with Section 8, Paragraph 1 of the Animal Welfare Act, German Civil Code 1. IS 01484 (experiment \#08/1604).

After manufacturing the degradable magnesium scaffolds (Figures 1 and 2), a left ventricular transmural defect in six Lewe minipigs was covered with a vascularised segment of the autologous stomach (Figures 1 and 3). The native vascular supply of the stomach via the left epigastric vein and artery was maintained. To stabilise this biological graft, magnesium structures were fixed to the epicardium over the reconstructed area (Figures 1-3).

Subsequently, the degradation of the magnesium structures, the biological reactions of the surrounding cardiac muscle to the metallic implant, and the integration and vascularisation of the biological graft as well as the heart function were examined three months and six months following transplantation.

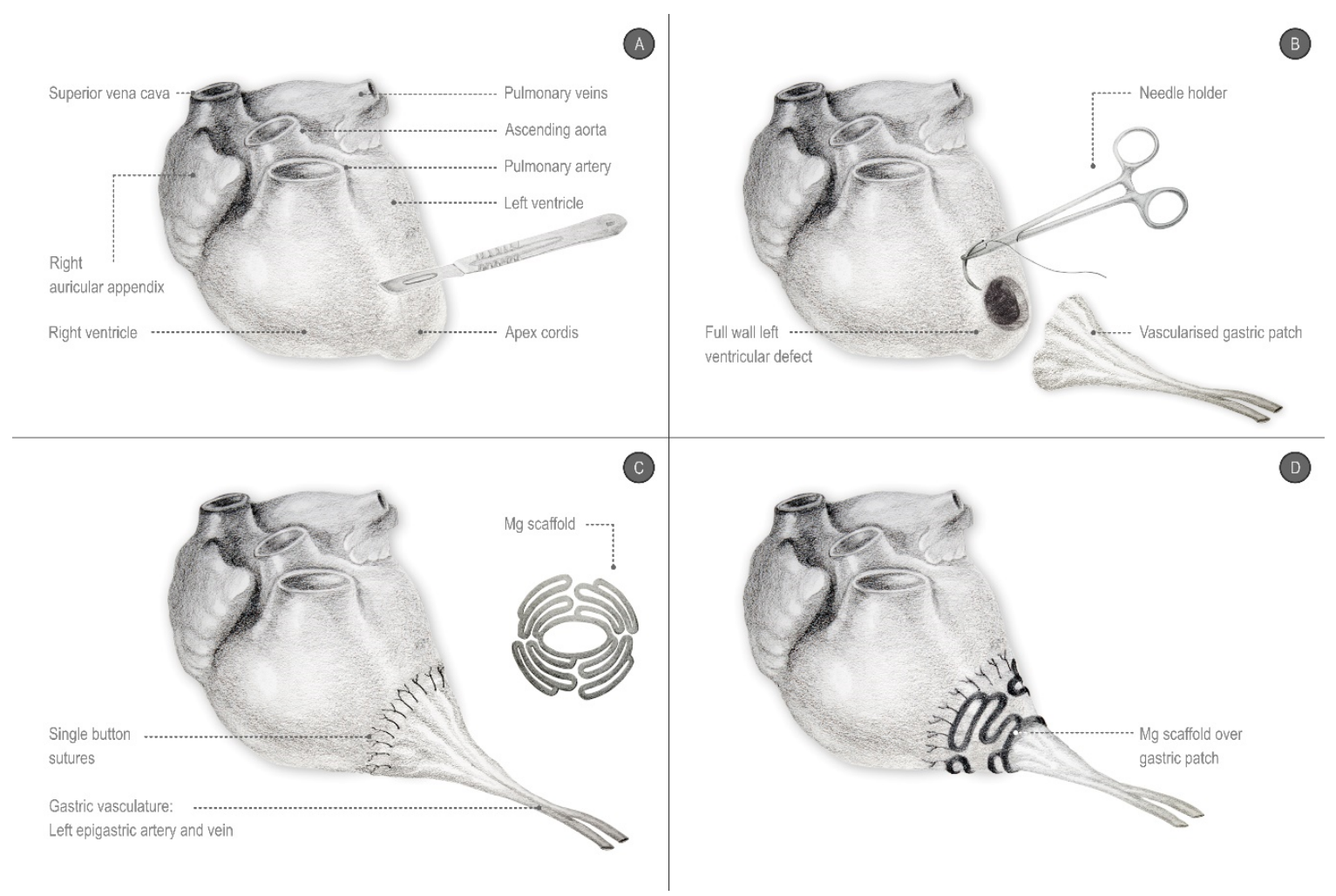

Figure 1. Drawing of the surgical approach. (A) Full wall incision of the left ventricle. (B) Suturing a vascularised autologous gastric patch on the left ventricle to cover the defect. (C,D) Stabilizing the delicate biological patch with a degradable magnesium scaffold. 


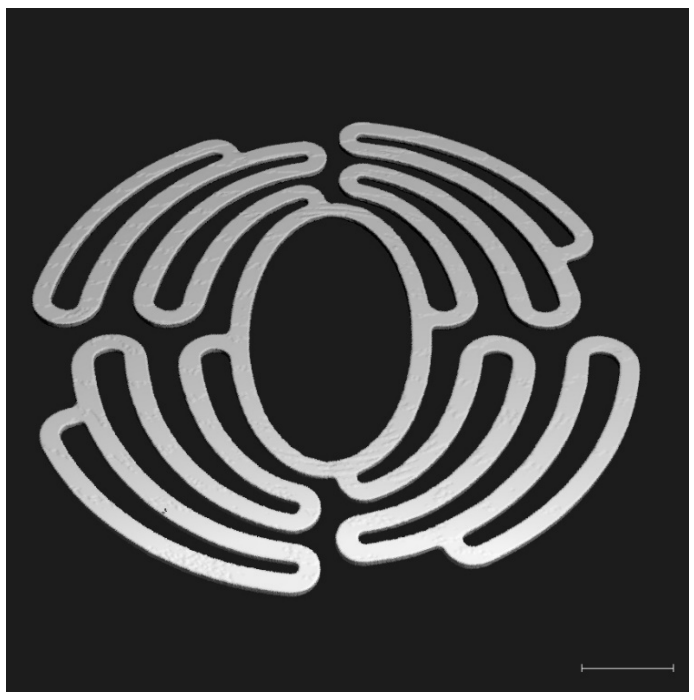

Figure 2. Reconstruction of the $\mu$-CT (Micro Computertomography) data of a magnesium scaffold prior to implantation. Bar indicates $5 \mathrm{~mm}$.

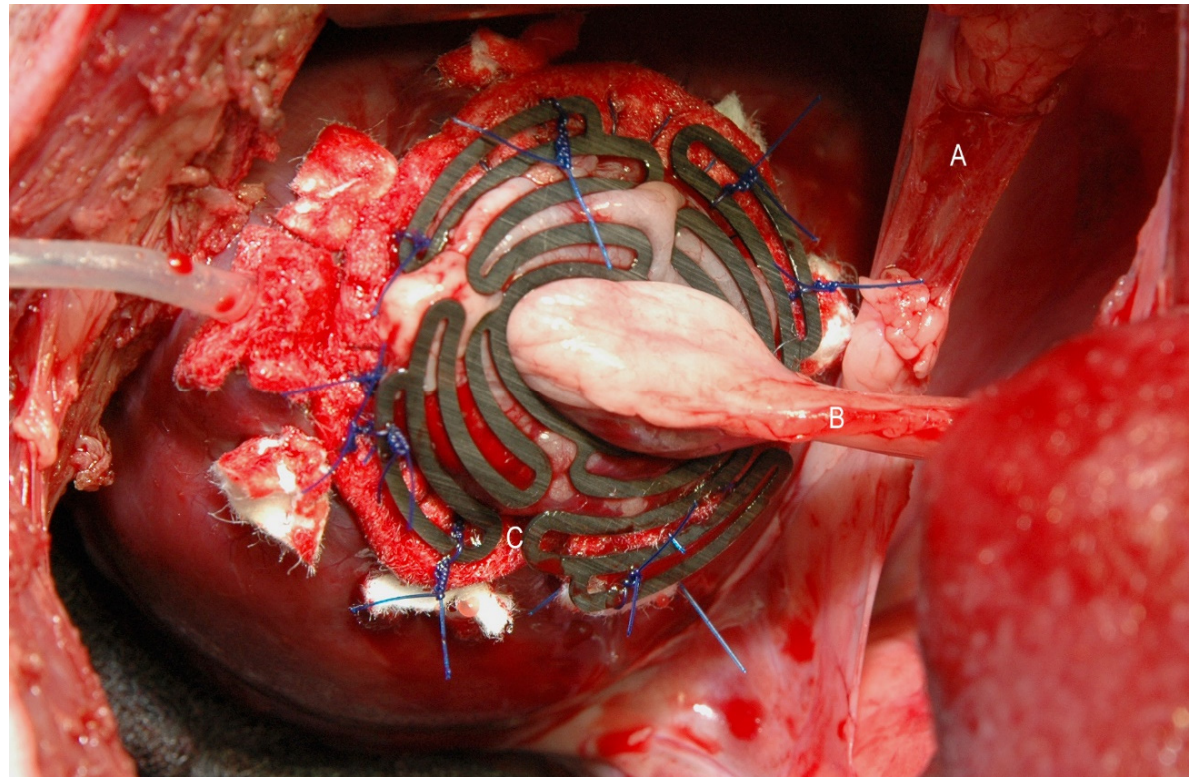

Figure 3. Operative situs using a degradable magnesium scaffold (C) to stabilise an autologous vascularised segment of the stomach (B), which served as a myocardial prosthesis. The gastric section was mobilized into the thoracic cavern via the diaphragm (A).

\subsection{Manufacturing of Magnesium Scaffolds}

The construction of the magnesium scaffolds has been described in detail elsewhere [10]; the scaffolds were made from sheets of magnesium alloy LA63 ( $6 \mathrm{wt} \%$ lithium, $3 \mathrm{wt} \%$ aluminium) with a thickness of $1 \mathrm{~mm}$. The scaffolds were shaped by abrasive water jet cutting using a high pressure water jet pump (Type $20 \mathrm{XW}$ Waternife, Flow, Kent, WA, USA) under a maximum water pressure of $400 \mathrm{MPa}$ and a maximum flow rate of $7.8 \mathrm{l} / \mathrm{m}$ at ambient temperature. The water jet nozzle diameter was $0.17 \mathrm{~mm}$ using a focusing tube of $0.6 \mathrm{~mm}$. Garnet mesh \#120 (GMA Garnet (Europe) $\mathrm{GmbH}$, Hamburg, Germany) was added to the water jet as an abrasive with a flow rate of $150 \mathrm{~g} / \mathrm{min}$ (Figure 2). The scaffolds' surfaces were then transformed to magnesium fluoride as a coating layer with 40\% hydrofluoric acid (Carl-Roth GmbH \& Co. KG, Karlsruhe, Germany) for 96 h. The magnesium scaffolds were subsequently sterilized with gamma radiation at a dose of $25 \mathrm{kGy}$ at room temperature for $8 \mathrm{~h}$ with a cobalt gammaradiation source according to DIN EN ISO 11137-2 (German Institute for 
Standardization, European Norm, International Organization for Standadization). The scaffolds were then stored in a sterile package at room temperature until implantation.

\subsection{Implantation}

The anaesthetic regimen and preoperative and postoperative measures applied to the six $35 \mathrm{~kg}$ Lewe minipigs to prevent arrhythmia, infection, pain, or gastric ulcers, as well as the wound closure, have already been described in detail elsewhere [9].

A median laparotomy was performed to prepare an approximately $4 \times 4 \mathrm{~cm}$ large segment of the stomach originating from the gastrosplenic ligament. The laparotomy was then extended to a left lateral thoracotomy in the fourth intercostal space. After systemic heparinization (400 IU/kg; heparin sodium 25,000, Ratiopharm, Ulm, Germany), an extracorporeal circulation (Stöckert S3, Sorin Group Germany $\mathrm{GmbH}$, Munich, Germany) was applied via the carotid artery and the right atrium. The body temperature of the animal was cooled down to $28^{\circ} \mathrm{C}$.

First, a transmural and nearly circular defect measuring approximately $4 \times 4 \mathrm{~cm}$ was produced in the anterolateral wall of the left ventricle. The diaphragm was incised, and the prepared segment of the stomach, including its native vascular supply via the left epigastric artery, was positioned through this incision into the thoracic cavity. The stomach was then closed with a continuous suture (Polyprolene 2.0, Ethicon, Hamburg, Germany). The stomach segment was mechanically freed from its mucosa with a scalpel and drawn through the central ellipsoid opening of the magnesium scaffold. The circular transmural defect of the left ventricle was then covered with the stomach segment. The vascularised stomach segment was fixed with a continuous suture (Polypronlene 4.0, Ethicon, Hamburg, Germany) to the myocardium. To stabilise the stomach segment against the high intraventricular pressure, the magnesium scaffold—still hanging loosely around the pedicle-was pushed forward until it rested with its outer edges on the epicardium and finally sutured with 4 simple interrupted stitches (Polyprolene 4.0, Ethicon, Hamburg, Germany) to the epicardium, each approximately $5 \mathrm{~mm}$ beyond the border zone between the stomach and myocardium (Figure 3).

After the transposition of the stomach segment and the fixation of the magnesium scaffold, the systemic heparinisation was antagonised with $400 \mathrm{IU} / \mathrm{kg}$ of protamine (Medapharma, Wangen-Brüttisellen, Switzerland). Finally, a precise bleeding control, rewarming to $37^{\circ} \mathrm{C}$, weaning from the heart-lung machine, and wound closure were performed. For this purpose, the ribs were adapted (Mersilene 2.0, Ethicon, Hamburg, Germany), the muscle layers closed with a continuous suture (Vicryl 2.0, Ethicon, Hamburg, Germany), and, after performing a skin closure according to the Donati technique (CBX1 Vicryl, Ethicon, Hamburg, Germany), the wound was covered with aluminium spray (Almapharm, Wildpoldsried, Germany).

After this two-cavity operation, three animals were scheduled for euthanasia after three months (3M group), and another three animals after six months (6M group).

\subsection{Cardiac Magnetic Resonance Imaging (MRI)}

The laboratory animals were examined by MRI directly before euthanasia 3 (3M group) and 6 (6M group) months following surgery, respectively. To immobilise the animals during examination, they were sedated with intravenous Propofol Lipuro $(1 \mathrm{~mL} / \mathrm{kg} / \mathrm{h}$, Braun, Melsungen, Germany), intubated, ventilated, and then placed into the MRI scanner in the left lateral position. The MRI scan was performed in a 1.5 Tesla MR scanner (Genesis Signa CVI, GE Healthcare, Braunschweig, Germany). The objective of the scan was to evaluate the morphology, function, and tissue characteristics of the left ventricle, particularly of the patch region. For the quantitative assessment of the left ventricular volumes and ejection fraction, as well as for the visual evaluation of the morphology and wall motion an ECG-gated, a breath-hold balanced steady-state free precession (SSFP) gradient-echo sequence (FIESTA) in standard short-axis view and two and four-chamber view was used. The following parameters were used: TR $3.9 \mathrm{~ms}$, TE $1.6 \mathrm{~ms}$, flip angle of 40 degrees, acquisition matrix $224 \times 224$, reconstructed matrix $512 \times 512$, and slice thickness $8 \mathrm{~mm}$. 
For the visual differentiation between the vital myocardium and fibrotic areas, an ECG-gated breath-hold contrast-enhanced T1-weighted inversion recovery gradient echo (IRGE) in the standard view was used. For this, the exposures were made about 10 to $20 \mathrm{~min}$ after the intravenous administration of a gadolinium-based MRI contrast agent (Gadobutrol; Gadovist, Bayer Vital GmbH, Leverkusen, Germany; dose of $0.15 \mathrm{mmol} / \mathrm{kg}$ body weight). The measurements were made using the following parameters: TR $7.2 \mathrm{~ms}$, TE $3.1 \mathrm{~ms}$, flip angle 20 degrees, acquisition matrix $256 \times 192$, reconstructed matrix $256 \times 256$, and slice thickness $8 \mathrm{~mm}$. The inversion time (IT) was correspondingly adjusted to zero the signal intensity of the healthy myocardium and was between 200-300 ms.

For the quantitative evaluation of the left ventricular volume and ejection fraction, the software CVI42 version 5.1.2 (Circle Cardiovascular Imaging Inc., Calgary, Canada) was used. The endocardial and epicardial contours in the end-systolic and end-diastolic phase were traced in the short-axis layers above the left ventricle from the atrioventricular junction to the apex. The morphology of the left ventricle, the regional wall motion, and the extent and distribution of the late enhancement were visually assessed.

\subsection{Angiography}

After three months (3M group) and after six months (6M group), the perfusion of the transplanted gastric segment was examined by angiography immediately before the euthanasia of the animals. Under the general anaesthesia already described in detail elsewhere [9], a median sternotomy was performed to expose the heart with the transplanted stomach segment and the magnesium structure or its residues. After the preparation of the pedicle of the heterotopically transplanted stomach segment, the inherent left epigastric artery was exposed. The artery was incised and a cannula (Vasofix ${ }^{\circledR}$ Safety, $22 \mathrm{G}$, B. Braun, Melsungen, Germany) was inserted in the antegrade direction and used for the application of a non-ionic contrast medium (Imeron $350^{\circledR}$, bracco-Byk Gulden, Konstanz, Germany). An X-ray was performed using the C-arm system (Ziehm Imaging $\mathrm{GmbH}$, Nürnberg, Germany).

\subsection{Explantation of the Heart, Including the Heterotopically Applied Segment of the Stomach and the Remains} of the Degradable Magnesium Scaffold

To explant the heart with the transplanted stomach segment and the stabilising scaffold or its remains, first the adhesions between the epicardium, pericardium, stomach patch, and visceral pleura were thoroughly removed. The euthanasia of the test animals was then performed by an injection of pentobarbiturate ( $450 \mathrm{mg} / \mathrm{kg}$ body weight, WDT, Garbsen, Germany). The whole heart was removed after severing the pedicle from the stomach segment, the ascending aorta, the superior and inferior vena cava, and the pulmonary vessels. The transplanted stomach segment was separated from the myocardium, leaving a rim of about $1 \mathrm{~cm}$.

\section{6. $\mu$-CT (Micro Computertomography)}

Immediately after explantation, the isolated portion of the left ventricular myocardium, including the stomach patch and magnesium scaffold or its remains, were examined in the $\mu \mathrm{CT}$ ( $\mu$-CT81, Scanco Medical AG, Brüttisellen, Switzerland). The exact procedure and the parameters have already been described in detail elsewhere [9]: Each layer was scanned for $1 \mathrm{~s}$ at a voltage of $55 \mathrm{kV}$ and a current of $72 \mu \mathrm{A}$. The thickness of the sections was 36 microns in each case.

All the magnesium structures had been scanned prior to implantation to determine the initial volume. The volume of the magnesium structures remaining in the explant was determined, and the $\mu$-CT data were reconstructed in a three-dimensional image with the proprietary software of the computer tomograph (Scanco Medical AG, Brüttisellen, Switzerland).

\subsection{Histology}

The implanted regions in contact to the surrounding cardiac wall of the left ventricle were dissected and carefully relieved from the metallic material. After fixation with $2.5 \%$ glutaraldehyde (Polysciences, 
Warrington, WA, USA) in $0.1 \mathrm{M}$ of sodium cacodylate of $\mathrm{pH} 7.3$ (Th. Geyer, Hamburg, Germany) for $4 \mathrm{~h}$ at room temperature, the specimens were rinsed in $0.1 \mathrm{M}$ of sodium cacodylate and postfixed with $2 \%$ osmium tetroxide (Polysciences Europe $\mathrm{GmbH}$, Hirschberg an der Bergstrasse, Germany) in $0.1 \mathrm{M}$ of sodium cacodylate. After dehydration in graded ethanols (Baker, Deventer, The Netherlands), they were embedded in epoxide resin (Serva GmbH, Heidelberg, Germany). The semithin sections were stained with 1\% Toluidine Blue (Merck KGaA, Darmstadt, Germany) and analyzed with an Axiovert 200M microscope (Carl Zeiss AG, Oberkochen, Germany). Representative micrographs were documented with Axiovision 4.8.2 and processed with Adobe Photoshop CS6 (Adobe Systems GmbH, Munich, Germany).

\section{Results}

\subsection{Clinical Results and Macroscopic Findings}

All six operated animals survived surgery and the respective planned postoperative observation period until euthanasia without significant clinical complications. Just a few days after the operation, the animals were already showing normal movement and feeding behaviour. There were no signs of paralysis or other neurological abnormalities. Wound healing disturbances or wound infections were not observed.

The explanted heart showed significant fibrotic transformations in the sense of scar tissue in the area of the transplanted autologous stomach segment. The preparation of the graft was considerably difficult due to the extensive adhesions between the stomach segment, the epicardium, the pericardium, and the pleura (Figure 4). In the peripheral zone of the stomach graft, the scar tissue presented irregular accumulations of small vesicles (Figure 4). The stabilizing magnesium scaffold was completely covered with scar tissue. Neither any part of the stabilizing structure nor degradation residues like magnesium fragments or particles were macroscopically visible.

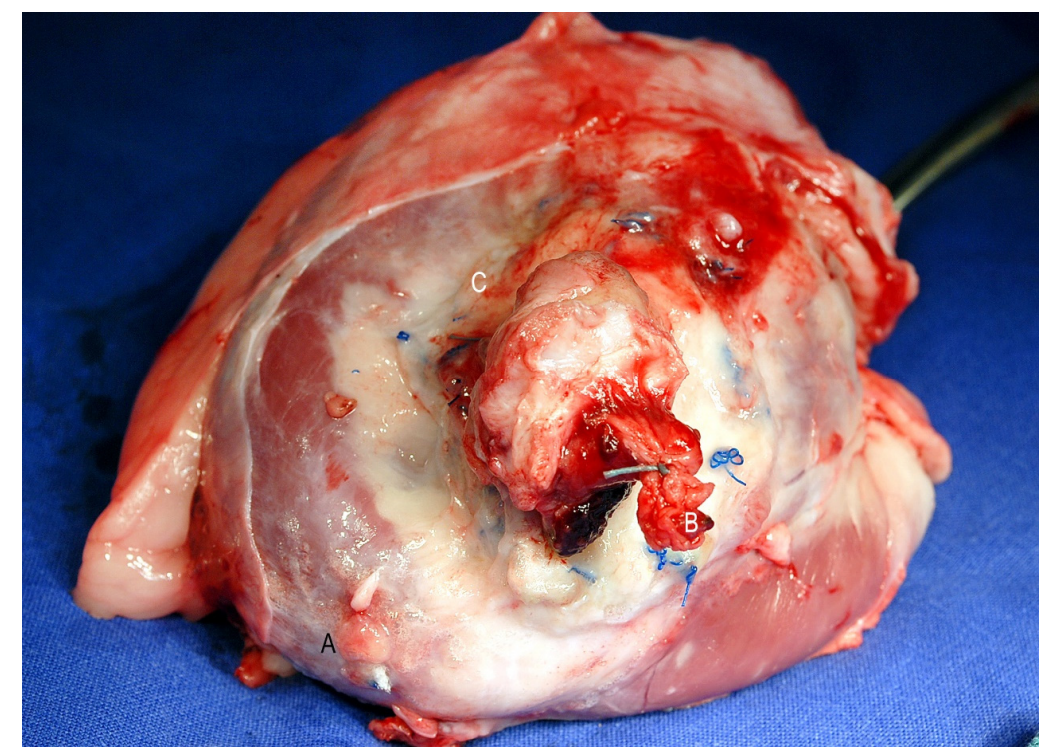

Figure 4. Explanted heart 6 months after the transplantation of the autologous vascularised stomach segment and implantation of the stabilising magnesium structure. Antero-inferior view. (A) Apex cordis. Irregular clustering of small vesicles in the border zone of the cicatricial tissue between the native myocardium and the gastric patch. (B) Cut off pedicle of the gastric patch with arterial and venous vessels. (C) Scarred junction between the left ventricular myocardium and the stomach tissue.

After opening the heart and exposing the left ventricle, an aneurysm of the implanted gastric muscular layer was detected at the luminal side of the left ventricle in one of the three animals of the $3 \mathrm{M}$ group and in two of the three animals of the $6 \mathrm{M}$ group (Figure 5). A paradoxical movement of the 
stomach tissue could be observed in the animals with the aneurysms. The other animals, in contrast, showed a complete scarred closure of the transmural myocardial defect.

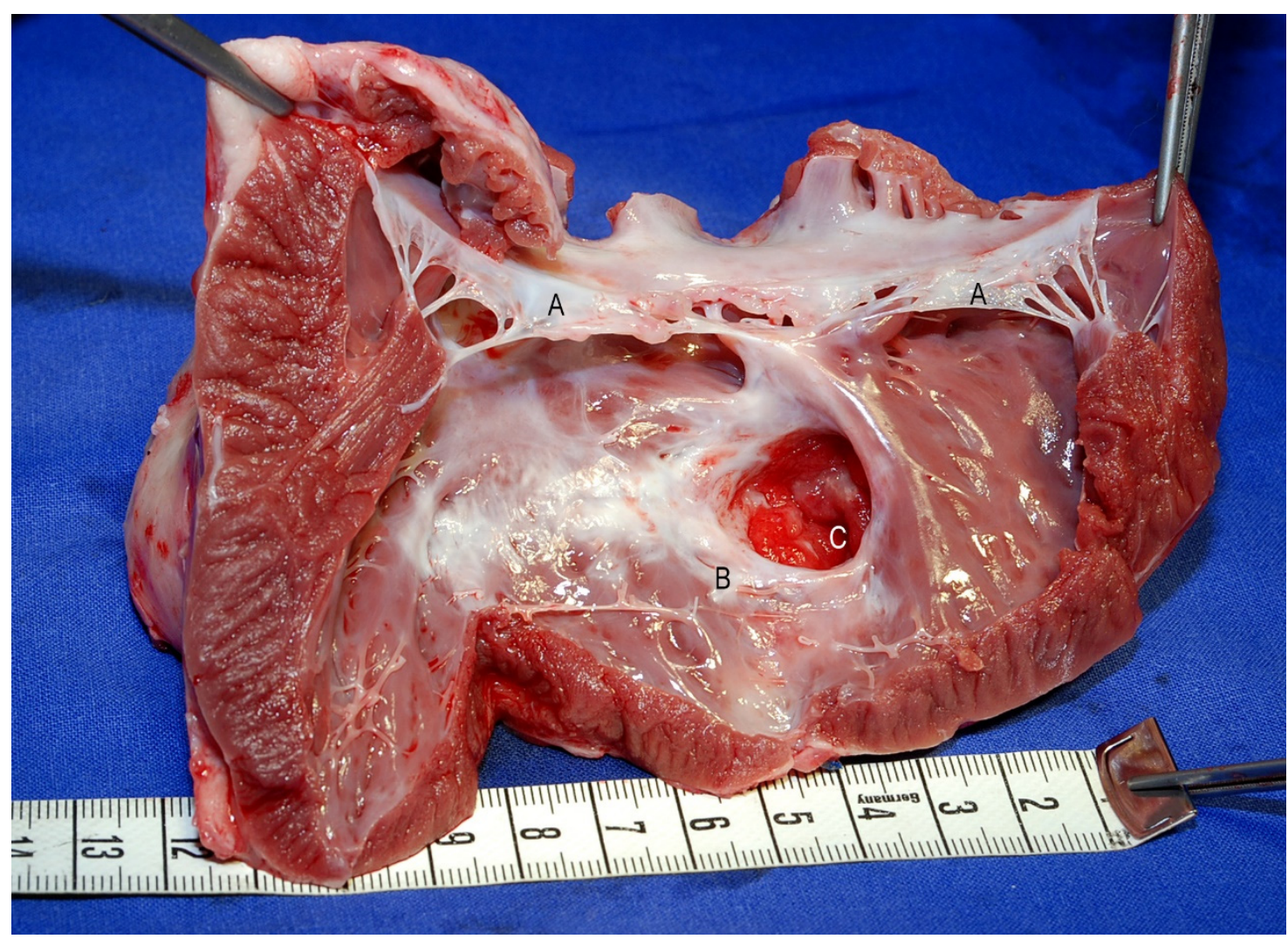

Figure 5. Explanted heart with a luminal view on the region with the transplanted gastric patch after the 6 month observation period. (A) Mitral valve leaflet; (B) scarred border zone between myocardium and stomach tissue; (C) moderate aneurysm of the stomach tissue and incomplete closure of the transmural ventricular defect. Typical pleated aspect of the tunica muscularis of the stomach.

No cases showed any signs of infection, necrosis, or thrombus in the area of the graft. The tunica muscularis of the stomach segment was covered with a delicate and smooth layer of endothelial cells on the luminal side.

\section{2. $M R I$}

Before euthanasia, the test animals were examined by a cardiac MRI to determine the volume and functional data of the left ventricle. Stable integration of the stomach patch through adjacent scar tissue could be detected already after three months following implantation (Figure 6). The late enhancement of the contrast medium in this tissue area was a clear indication of fibrotic remodelling processes (Figure 7). All the animals without aneurysm formation showed normal left ventricular volume values as well as normal left ventricular ejection fractions. However, reduced motility of the ventricular wall in the junction area between the cardiac muscle and graft could be observed in all animals. 

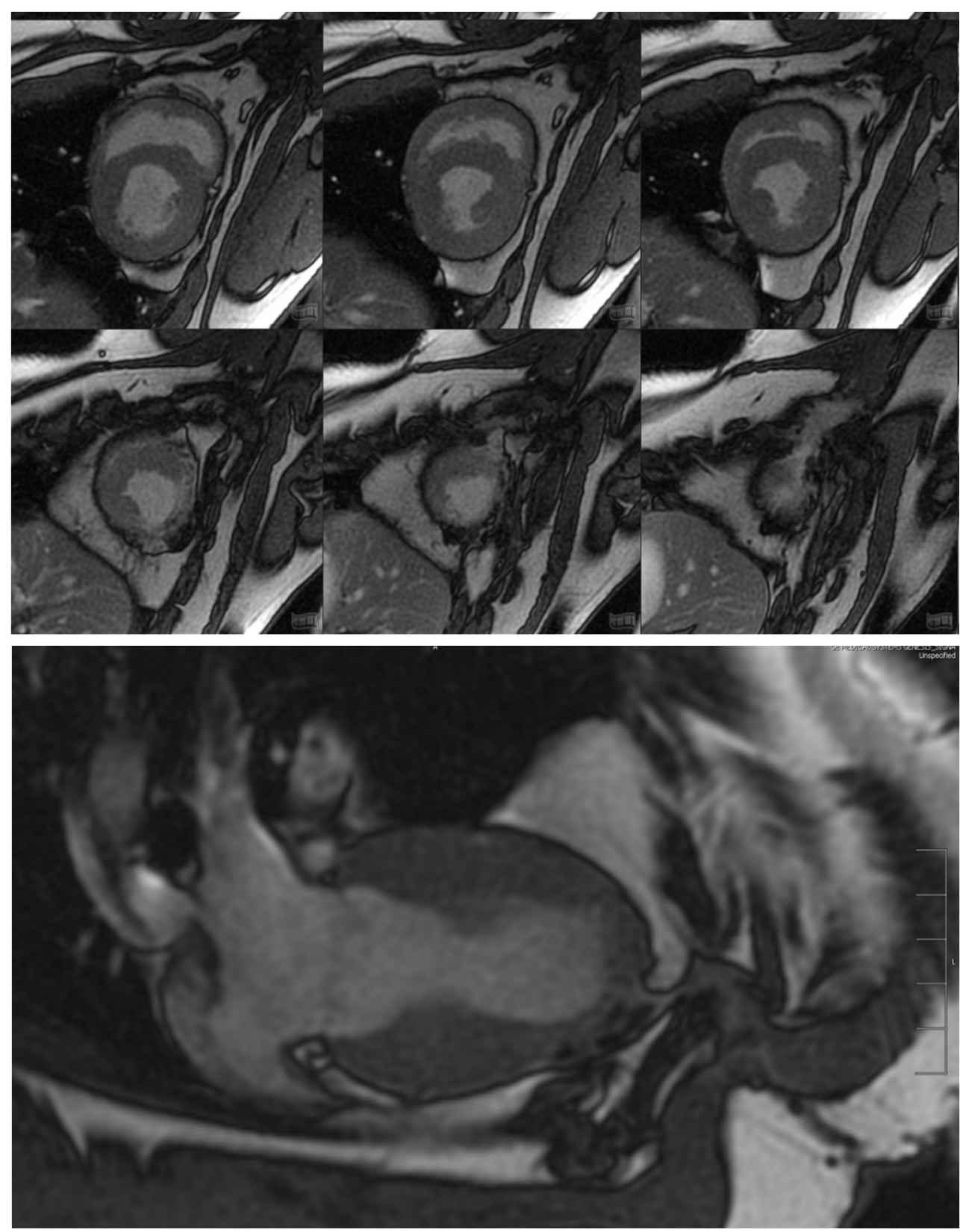

Figure 6. Cardio MRI three months following the reconstruction of the myocardium with an autologous vascularised gastric patch and stabilisation with a degradable magnesium scaffold. Top: Cine steady-state free precession (SSFP) in short axis from midventricular to apex cordis. Bottom: Cine SSFP with left ventricular two-chamber view. Good integration of the transplanted gastric patch. 

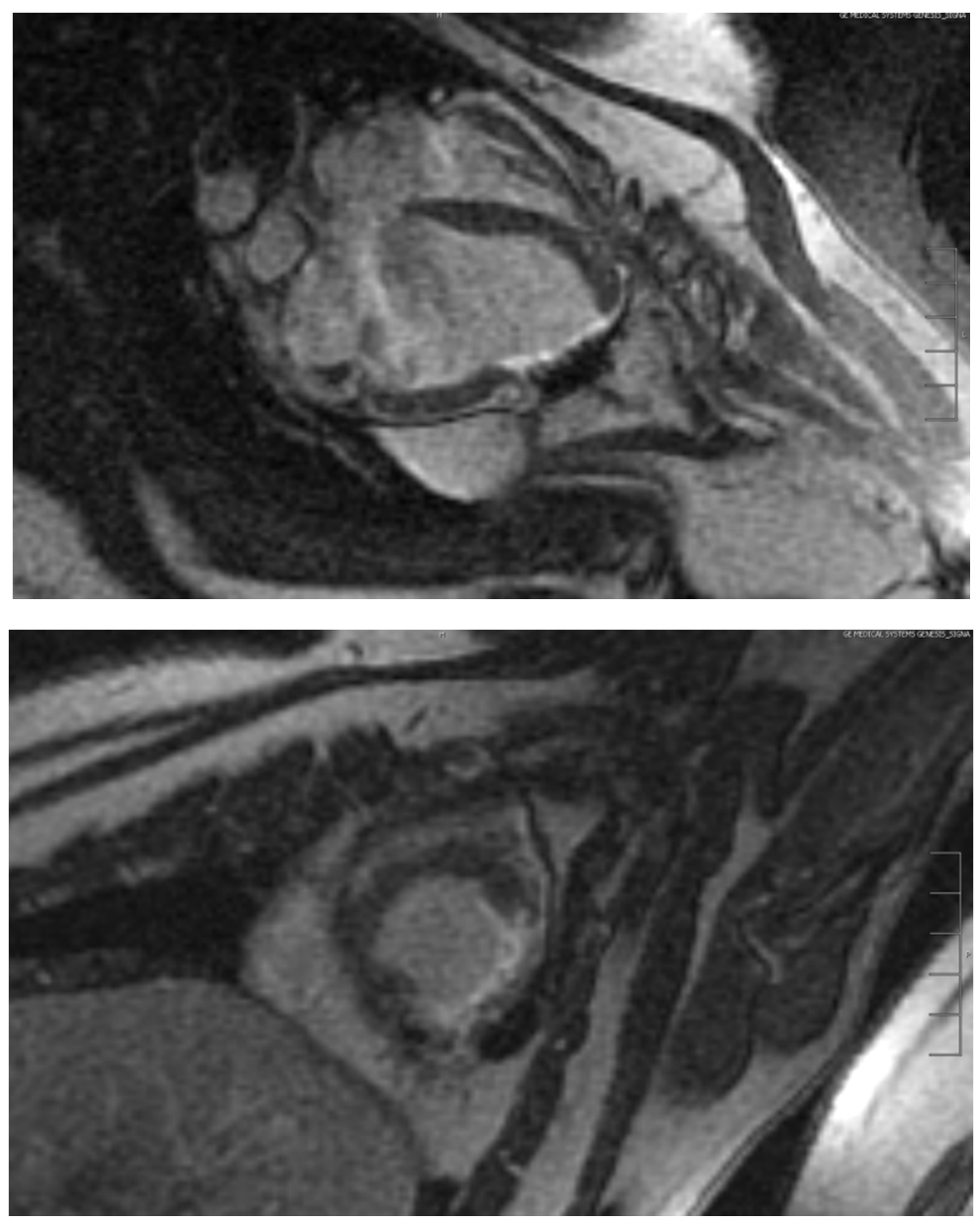

Figure 7. Cardio MRI with delayed enhancement imaging 6 months following the reconstruction of the myocardium with an autologous vascularised gastric patch, and stabilisation with a degradable magnesium scaffold. Top: Four-chamber view with evidence of a significant ribbon-like late enhancement from apex cordis until the middle of the left ventricle, indicating fibrotic remodelling in the border zone between the myocardium and the transplanted gastric patch.

Three animals featured aneurysmal outpouching in varying degrees of severity in the area of the transplanted stomach tissue. The animal with the largest aneurysm in the area of the transplanted stomach tissue showed a significant increase in its end-diastolic and end-systolic volume, a significant reduction in stroke volume, and consecutively a significant decrease in the left ventricular ejection fraction to $36.4 \%$. The animal that had developed the smallest aneurysm with a volume of only $6.8 \mathrm{~mL}$ showed no reduction in its left ventricular pump function (LV-EF 61.8\%).

\subsection{Angiography}

The contrast agent administered to the left epigastric artery revealed a good openness of the branches supplying the stomach graft in all the examined animals. The stomach segment was excellently supplied with blood both in the $3 \mathrm{M}$ and in the $6 \mathrm{M}$ group. Besides this, The contrast agent administered to the left epigastric artery flooded into the native coronary arteries (Figure 8). This indicates an in vivo anastomosis of the two different vascular systems. 


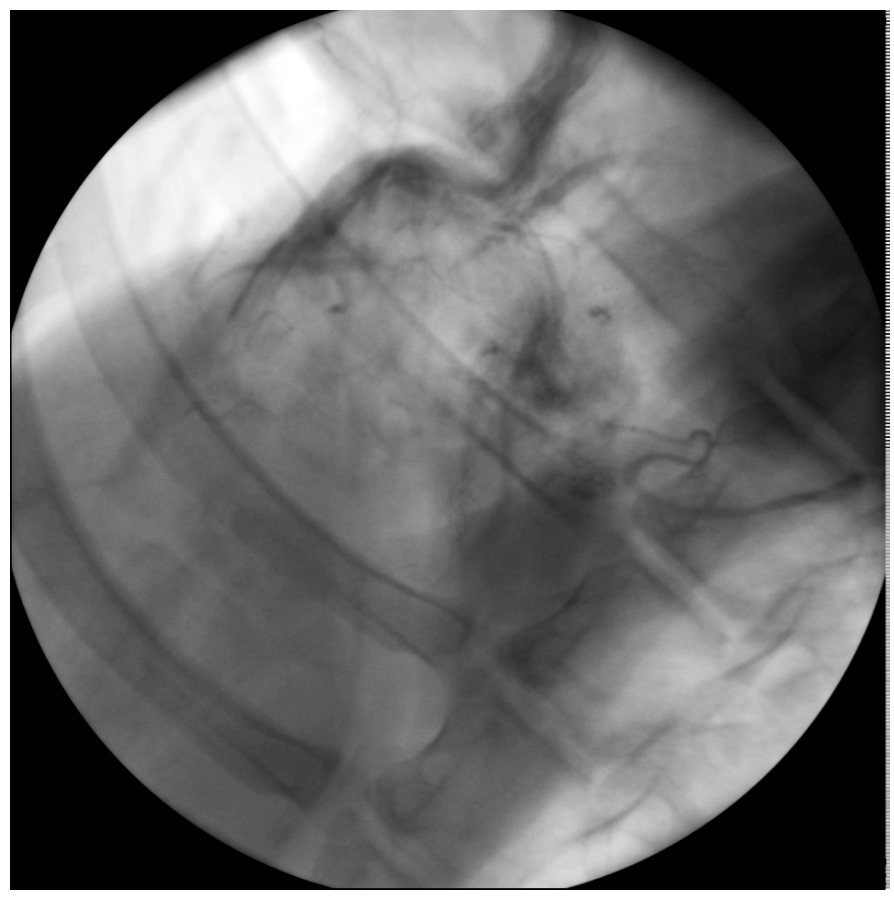

Figure 8. Angiography 3 months after implantation. Retrograde flooding of the contrast agent from the gastric patch artery into the coronary vasculature of the heart.

\section{4. $\mu C T$ Investigation}

The initial volumes of all the magnesium scaffolds were determined using micro-computed tomography and amounted to an average of $260.68 \mathrm{~mm}^{3}$ (standard deviation: 16.95). Three months following implantation, a percentage of 35.24 , and after six months, $26.57 \%$, of the original volume of the magnesium structure could still be detected by computed tomography in the explant (Figure 9).

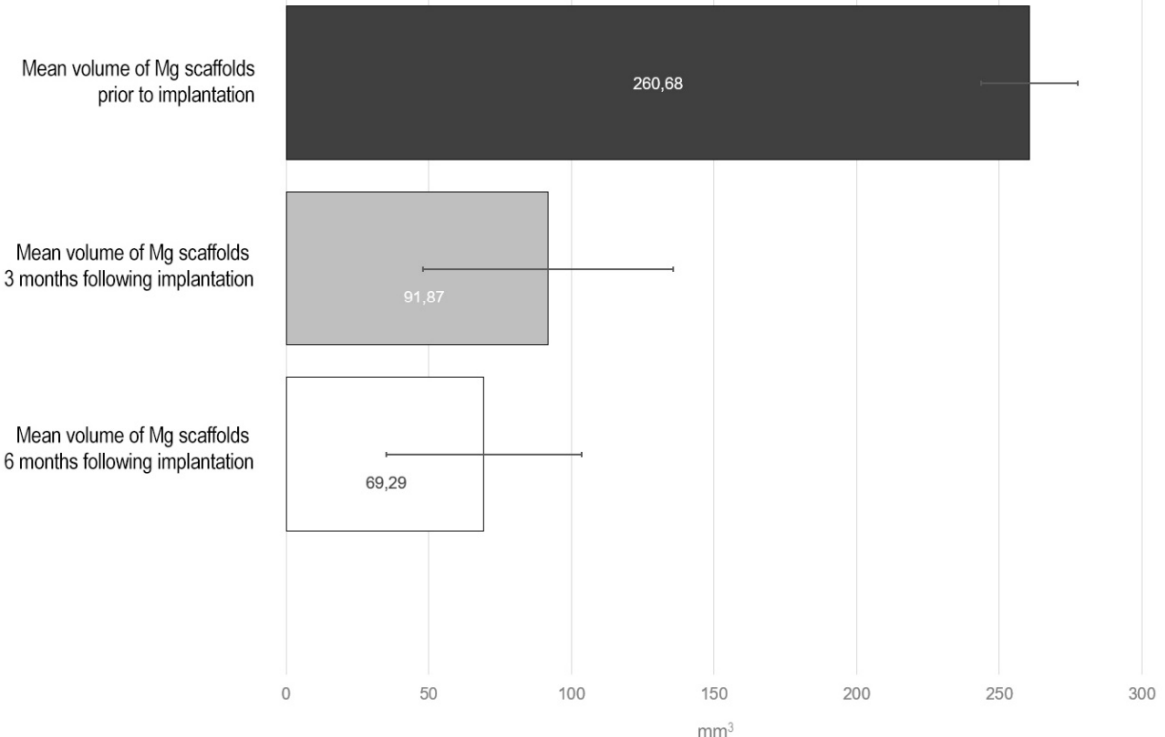

Figure 9. Comparison of the mean volumes of the magnesium scaffolds before implantation (dark grey), three months following implantation (light grey), and six months following implantation (white) in $\mathrm{mm}^{3}$. 
Three months after implantation, the magnesium structure was already significantly degraded, thus canceling the structural integrity. Only occasionally could the shape of some arms and segments of the meandering structure could still be seen, while large areas were made up of clouds of granules or powder from the original structure (Figure 10a).
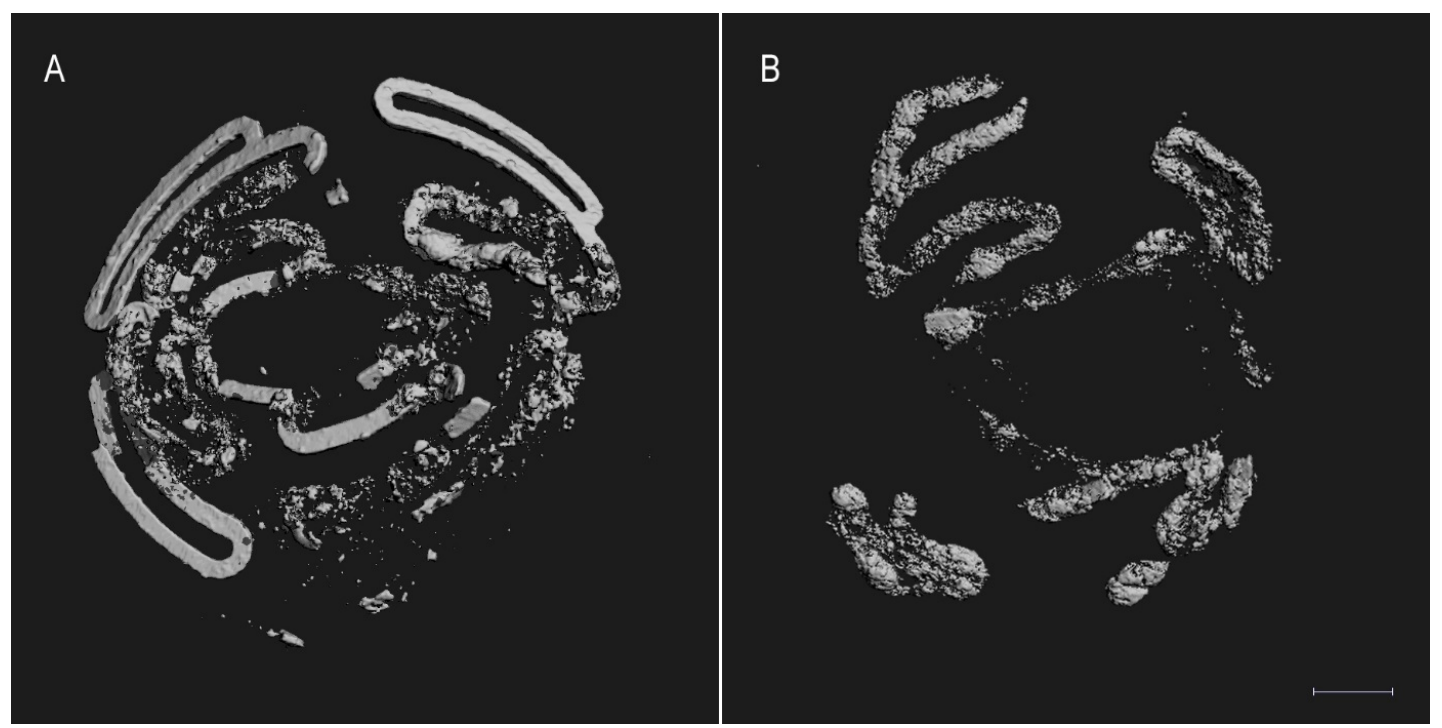

Figure 10. Reconstruction of the $\mu-\mathrm{CT}$ data of the explanted tissue with residual magnesium scaffolds 3

(A) and 6 (B) months following implantation. Bar indicates $5 \mathrm{~mm}$.

After six months, coherent metallic structures were barely visible and primarily cloud-like accumulations of grains and powder could be found (Figure 10b).

\subsection{Histology}

The granulomatous inflammation was restricted around the metallic implants covering the myocardial tissue and the muscular layer of the gastric implant, respectively. Three months after implantation, a distinct layer of macrophages and single giant cells were in direct contact with the macroscopically identifiable metallic surfaces (Figure 11a). Necrosis or gas bubbles could not be recognized in the surrounding tissue. Six months following implantation, no compact metallic fragments were visible. Nevertheless, granulomas had been formed within the granulomatous tissue, containing predominantly macrophages and single giant cells (Figure 11b). Numerous activated microvessels, as well as fibroblasts producing a collagen-rich extracellular matrix, could be seen in the surrounding connective tissue.

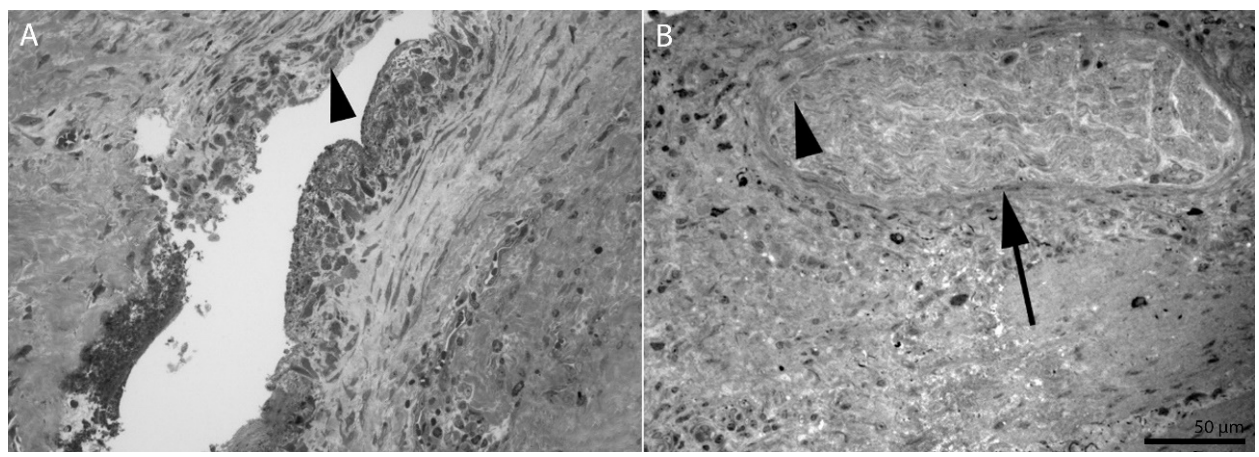

Figure 11. A layer of granulomatous tissue completely separated the metallic implant from the cardiac wall. Three months after implantation, single giant cells (arrowhead in A) are visible between plenty of macrophages. After 6 months, the separated granulomas (arrow in B) are filled predominantly with myofibroblasts and single giant cells (arrowhead in B). 


\section{Discussion}

Since the 1930s, there have been attempts to support damaged heart muscle with regenerative biological grafts or even to reconstruct it [11]. Until now, however, due to the low mechanical stability of biological grafts, transmural myocardial repair has been limited to the right ventricle or atrium $[6,8,12,13]$. The reconstruction of the right ventricle with stomach tissue has already been clinically implemented as a last resort. In contrast, the treatment of the dysfunctional left ventricle with biological myocardial prostheses primarily aimed to improve the pumping function and vascularisation of the scarred myocardium so far. The tissues were placed merely epicardially on the damaged area in these cases [11,14-22]. Ruel et al. used a ligation of the circumflex coronary artery in a swine model to induce infarction and then supported the infarcted myocardium with vascularised stomach, which they fixed epicardially on the dysfunctional area [21]. Unlike Ruel et al., our approach was to use a segment of vascularised stomach for the transmural reconstruction of a left ventricular defect in a demanding two-cavity surgical procedure, which all animals survived in good clinical condition. No test animal showed any clinical evidence of hemodynamic insufficiency. Presumably, the reduced physical activity due to indoor confinement may have masked the expected reduced performance of those animals with a critically low left ventricular ejection fraction. Nonetheless, a distinctive remodelling did take place; cellular granulation tissue was formed between the native myocardium and stomach, which was also penetrated by numerous capillaries and neocapillaries, thus anastomosing the vasculature of both tissues. We were even able to find a retrograde uptake of the contrast medium that we had injected via the left epigastric artery of the stomach graft in the native coronary vessels angiographically. Therefore, a functional connection of the vascular system of the stomach to the coronary arteries must also be assumed. It remains unclear to what extent this active remodelling, the vigorous scar tissue in the border zone between the myocardium and gastric patch, and the stabilising magnesium scaffold prevented the formation of an aneurysm.

The stabilising magnesium structure prevented the rupture of the delicate transplanted stomach tissue in all cases. Nevertheless, we still diagnosed an aneurysm after a period of three and six months. It cannot be ruled out that the epicardial surgical fixation of the structure was carried out inadequately or not in accordance with the actual mechanical stress conditions. Possibly, more extensive meshes are required spanning a larger area of the still-healthy myocardium. This extensive approach has been adopted with the Paracor heartnet, which is designed to prevent further dilatation in heart failure patients $[23,24]$.

We not only found a loss of volume in the structure of $64.76 \%$ after three months and $73.42 \%$ after six months but also a substantial disintegration of the original scaffold using $\mu$-CT scans and histological analyses of the explants. The corrosion of magnesium alloys is subject to a specific time $[25,26]$. Most magnesium alloys show greater stability in the initial phase, while, subsequently, the speed of corrosion increases. Thus, in a preliminary study, we were able to demonstrate one month after epicardial fixation in a swine model that the coated magnesium scaffold was structurally intact [9].

The corrosion of the metallic implants is also dependent on the mechanical load and shear forces $[27,28]$. Gu et al. were able to determine a corrosion rate of up to 10 times higher for magnesium alloys when they are subjected to mechanical stress [28]. The intense pressure fluctuations that the magnesium scaffold is exposed to during cardiac action in the early phase after implantation may thus have accelerated the degradation of the magnesium alloy. Finally, it cannot be ruled out that damage was inflicted to the protective layer of magnesium fluoride during implantation. Possible early cracks in the coating could have been starting points for the corrosion. After all, the magnesium structure was greatly bent during the implantation to adapt it to the cardiac geometry. This deformation may have also caused cracks in the magnesium fluoride layer and additionally posed an enormous strain on the magnesium grid [29].

About one litre of hydrogen gas is produced as a degradation product in the corrosion of one gram of magnesium. In the present study, irregular accumulations of small bubbles could not be seen on the explants. The gas formation may pose a serious problem in orthopaedic implants made of 
magnesium because the implants are naturally fit in the smallest possible bone channels or boreholes with not enough room for the gas [30]. Against this, gas formation does not limit the epicardial fixation of magnesium structures in our experiment. After all, the pericardial sac and the mediastinum offer enough space for the regional distribution of gas volumes resulting over a long period of corrosion [9]. According to Kuhlmann et al., there is an exchange with the gases of the surrounding tissue, such as nitrogen gas, oxygen, and carbon dioxide, immediately after the formation of hydrogen gas [31]. This diffusion reduces the concentration of hydrogen gas and any associated toxic effects on the adjacent cardiac tissue, which could be confirmed in the present as well as in the previous study [9].

Toxic effects may also result from the degradation products of the magnesium alloy and its coating. In the present study, we used a magnesium alloy with lithium and aluminium (LA63) which was coated with magnesium fluoride $\left(\mathrm{MgF}_{2}\right)$. Magnesium itself is ubiquitously present in the body and is a co-factor and an important component of intracellular enzymatic reactions. The magnesium fluoride coating of the magnesium alloy is supposed to slow down and homogenise the corrosion [32-34]. Fluoride is a physiologically occurring element in the body that has undisputedly good biocompatibility and is required, for example, for building bone structure. Lithium is used in magnesium alloys to alkalise the corrosion layer and thus slow down degradation [30]. Aluminium, in the alloy with magnesium, forms a phase and a protective aluminium trioxide layer $\left(\mathrm{Al}_{2} \mathrm{O}_{3}\right)$ on the alloy surface [35], which, according to Pardo et al., has an anticorrosive effect [36]. In addition, in proportions of up to $6 \mathrm{wt} \%$, aluminium provides the magnesium alloy with higher mechanical stability, as Zheng et al. have summarised [35]. Both lithium and aluminium, which, as components of drugs, are also ingested, only have adverse effects in high concentrations. For example, Feyerabend et al. found that lithium and aluminium have toxic effects on perivascular cells at a concentration of about $1000 \mu \mathrm{M}$ [37]. El Rahman et al. were able to show the neuropathological effects of accumulated aluminium in terms of Alzheimer's disease in a rat model [38]. However, the implanted magnesium scaffold in this study did not have a sufficiently toxic amount of lithium nor aluminium. Magnesium hydroxide, the main degradation product of the magnesium alloy LA63, first forms at the surface of the magnesium structure before it dissolves inside the tissue. Janning et al. confirmed, however, that the solubility of this compound is exceptionally low. Thus, there is also only a very slow precipitation in tissues with resulting biologically well-tolerated concentrations [39]. A cellular granulation tissue as part of the foreign body response to the implanted magnesium, as seen in our study, additionally reduced a possible toxic effect of the metallic implant or its degradation products by forming a barrier against the surrounding tissues. Thus, the remnants of the magnesium structure or solid degradation products could not be detected macroscopically in the explanted hearts in this work.

\section{Limitations}

Due to the number of animals used in this study, no statement of statistical significance can be made here. Merely the principle approach and the feasibility of this innovative method for the treatment of advanced heart failure can be shown in this pilot study. Besides this, the state of the stabilising scaffold after just a short period in the respective experimental groups is unknown, since $\mu$-CT scans have to be performed on the explant. The computed tomography cannot enable a clear differentiation between the original magnesium alloy and the corrosion products. The swelling of the originally flat and rather angular arms of the meander pattern can be explained by degradation products, mainly magnesium hydroxide. Therefore, the calculated volumes of the residual magnesium structures may still be overestimated six months after implantation.

\section{Conclusions}

As a consequence of an ageing population and the growing survival rate of patients with ischemic myocardial damage, a further increase in the prevalence of severe heart failure is expected in the future. The lack of availability of donor organs and the high risk of complications after the implantation of ventricular assist devices creates a growing demand for regenerative surgical procedures. The present 
study responds to this demand by examining the feasibility of a left ventricular myocardium replacement with autologous vascularised stomach. Magnesium alloy scaffolds were employed to support the biological graft to span the gap until its sufficient mechanical stability. The metallic implants and their corrosion proved to be biologically highly compatible in all respects and seem to affect neither the healing nor the vascularisation of the graft. However, after three months the magnesium structures were already degraded to such an extent that the stabilising effect presumably was impaired in some cases. The further optimisation of both the properties of the scaffolds and the surgical fixation technique could lead to a reliable approach to facilitate a broad spectrum of regenerative biological grafts to combat severe heart failure.

Author Contributions: Conceptualization: A.H., S.C., I.T., T.S., T.H., M.B.; Funding acquisition: T.S., A.H., T.H.; Data curation: M.B., D.H.; Formal analysis: M.B., D.H.; Investigation: T.S., I.T., S.C., D.H., T.M., M.B., G.B.; Methodology: A.H., I.T., S.C., T.S., T.M., T.H., M.B., F.W.; Project administration: T.S., T.H.; Supervision: A.H., F.W., T.H.; Validation: G.B., M.B.; Visualization: T.S., D.H., G.B., M.B.; Writing—original draft: T.S., D.H., G.B.; Writing-review and editing: M.B., I.T., S.C., T.M., F.W., A.H., T.H. All authors have read and agreed to the published version of the manuscript.

Funding: This research was funded by German Research Foundation, SFB599, project R7.

Acknowledgments: The excellent technical support of Klaus Höffler, Petra Ziehme, Astrid Dierks-Ketterkat, and Rosi Katt of the Department of Cardiovascular, Thoracic, and Transplantation Surgery, as well as Annette Oestereich and Frank Schröder of the Institute for Radiology of Hannover Medical School is highly appreciated. We also thank Luigi Angrisani and Christoph Klose of the Institut für Werkstoffkunde (Materials Science) of Leibniz Universität Hannover for facilitating the $\mu-C T$ investigations. Not least, we are grateful to Andre Bleich, Klaus Otto, Karl-Heinz Napierski, and Paul Zerbe of the central animal facility of Hannover Medical School for their competent support in performing the animal surgery and providing the excellent laboratory infrastructure. Finally, we are grateful to the German Research Foundation for funding this project.

Conflicts of Interest: The authors declare no conflict of interest.

\section{References}

1. Dor, V.; Saab, M.; Coste, P.; Kornaszewska, M.; Montiglio, F. Left ventricular aneurysm: A new surgical approach. Thorac. Cardiovasc. Surg. 1989, 37, 11-19. [CrossRef] [PubMed]

2. Dor, V. Surgery for left ventricular aneurysm. Curr. Opin. Cardiol. 1990, 5, 773-780. [CrossRef] [PubMed]

3. David, T.E. The use of pericardium in acquired heart disease: A review article. J. Heart Valve Dis. 1998, 7, $13-18$.

4. David, T.E.; Feindel, C.M.; Ropchan, G.V. Reconstruction of the left ventricle with autologous pericardium. J. Thorac. Cardiovasc. Surg. 1987, 94, 710-714. [CrossRef]

5. Schilling, T.; Cebotari, S.; Tudorache, I.; Haverich, A. Tissue engineering of vascularized myocardial prosthetic tissue. Biological and solid matrices. Chirurg 2011, 82, 319-324. [CrossRef] [PubMed]

6. Tudorache, I.; Kostin, S.; Meyer, T.; Teebken, O.; Bara, C.; Hilfiker, A.; Haverich, A.; Cebotari, S. Viable vascularized autologous patch for transmural myocardial reconstruction. Eur. J. Cardiothorac. Surg. 2009, 36, 306-311. [CrossRef]

7. Mertsching, H.; Schanz, J.; Steger, V.; Schandar, M.; Schenk, M.; Hansmann, J.; Dally, I.; Friedel, G.; Walles, T. Generation and transplantation of an autologous vascularized bioartificial human tissue. Transplantation 2009, 88, 203-210. [CrossRef]

8. Badylak, S.F.; Kochupura, P.V.; Cohen, I.S.; Doronin, S.V.; Saltman, A.E.; Gilbert, T.W.; Kelly, D.J.; Ignotz, R.A.; Gaudette, G.R. The use of extracellular matrix as an inductive scaffold for the partial replacement of functional myocardium. Cell Transplant. 2006, 15, S29-S40. [CrossRef]

9. Schilling, T.; Brandes, G.; Tudorache, I.; Cebotari, S.; Hilfiker, A.; Meyer, T.; Biskup, C.; Bauer, M.; Waldmann, K.H.; Bach, F.W.; et al. In vivo degradation of magnesium alloy LA63 scaffolds for temporary stabilization of biological myocardial grafts in a swine model. Biomed. Tech. (Berl.) 2013, 58, 407-416. [CrossRef]

10. Schilling, T.; Bauer, M.; Biskup, C.; Haverich, A.; Hassel, T. Engineering of biodegradable magnesium alloy scaffolds to stabilize biological myocardial grafts. Biomed. Tech. (Berl.) 2017, 62, 493-504. [CrossRef]

11. Beck, C.S. The development of a new blood supply to the heart by operation. Ann. Surg. 1935, 102, 801-813. [CrossRef] [PubMed] 
12. Kelly, D.J.; Rosen, A.B.; Schuldt, A.J.; Kochupura, P.V.; Doronin, S.V.; Potapova, I.A.; Azeloglu, E.U.; Badylak, S.F.; Brink, P.R.; Cohen, I.S.; et al. Increased myocyte content and mechanical function within a tissue-engineered myocardial patch following implantation. Tissue Eng. Part A 2009, 15, 2189-2201. [CrossRef] [PubMed]

13. Badylak, S.; Obermiller, J.; Geddes, L.; Matheny, R. Extracellular matrix for myocardial repair. Heart Surg. Forum 2003, 6, E20-E26. [CrossRef] [PubMed]

14. Dolan, E.B.; Hofmann, B.; de Vaal, M.H.; Bellavia, G.; Straino, S.; Kovarova, L.; Pravda, M.; Velebny, V.; Daro, D.; Braun, N.; et al. A bioresorbable biomaterial carrier and passive stabilization device to improve heart function post-myocardial infarction. Mater. Sci. Eng. C Mater. Biol. Appl. 2019, 103, 109751. [CrossRef] [PubMed]

15. Chachques, J.C.; Lila, N.; Soler-Botija, C.; Martinez-Ramos, C.; Valles, A.; Autret, G.; Perier, M.C.; Mirochnik, N.; Monleon-Pradas, M.; Bayes-Genis, A.; et al. Elastomeric cardiopatch scaffold for myocardial repair and ventricular support. Eur. J. Cardio-Thorac. Surg. 2019, 57, 545-555. [CrossRef] [PubMed]

16. Schaefer, J.A.; Guzman, P.A.; Riemenschneider, S.B.; Kamp, T.J.; Tranquillo, R.T. A cardiac patch from aligned microvessel and cardiomyocyte patches. J. Tissue Eng. Regen. Med. 2018, 12, 546-556. [CrossRef]

17. Tan, M.Y.; Zhi, W.; Wei, R.Q.; Huang, Y.C.; Zhou, K.P.; Tan, B.; Deng, L.; Luo, J.C.; Li, X.Q.; Xie, H.Q.; et al. Repair of infarcted myocardium using mesenchymal stem cell seeded small intestinal submucosa in rabbits. Biomaterials 2009, 30, 3234-3240. [CrossRef]

18. Suzuki, R.; Hattori, F.; Itabashi, Y.; Yoshioka, M.; Yuasa, S.; Manabe-Kawaguchi, H.; Murata, M.; Makino, S.; Kokaji, K.; Yozu, R.; et al. Omentopexy enhances graft function in myocardial cell sheet transplantation. Biochem. Biophys. Res. Commun. 2009, 387, 353-359. [CrossRef]

19. Taheri, S.A.; Yeh, J.; Batt, R.E.; Fang, Y.; Ashraf, H.; Heffner, R.; Nemes, B.; Naughton, J. Uterine myometrium as a cell patch as an alternative graft for transplantation to infarcted cardiac myocardium: A preliminary study. Int. J. Artif. Organs 2008, 31, 62-67. [CrossRef]

20. Kanamori, T.; Watanabe, G.; Yasuda, T.; Nagamine, H.; Kamiya, H.; Koshida, Y. Hybrid surgical angiogenesis: Omentopexy can enhance myocardial angiogenesis induced by cell therapy. Ann. Thorac. Surg. 2006, 81, 160-167. [CrossRef]

21. Ruel, M.A.; Sellke, F.W.; Bianchi, C.; Khan, T.A.; Faro, R.; Zhang, J.P.; Cohn, W.E. Endogenous myocardial angiogenesis and revascularization using a gastric submucosal patch. Ann. Thorac. Surg. 2003, 75, 1443-1449. [CrossRef]

22. Kusaba, E.; Schraut, W.; Sawatani, S.; Jaron, D.; Freed, P.; Kantrowitz, A. A diaphragmatic graft for augmenting left ventricular function: A feasibility study. Trans. Am. Soc. Artif. Intern. Organs 1973, 19, 251-257. [CrossRef]

23. Magovern, J.A. Experimental and clinical studies with the Paracor cardiac restraint device. Semin. Thorac. Cardiovasc. Surg. 2005, 17, 364-368. [CrossRef] [PubMed]

24. Atluri, P.; Acker, M.A. Diastolic ventricular support with cardiac support devices: An alternative approach to prevent adverse ventricular remodeling. Heart Fail. Rev. 2013, 18, 55-63. [CrossRef] [PubMed]

25. Rettig, R.; Virtanen, S. Time-dependent electrochemical characterization of the corrosion of a magnesium rare-earth alloy in simulated body fluids. J. Biomed. Mater. Res. A 2008, 85, 167-175. [CrossRef] [PubMed]

26. Makar, G.L.; Kruger, J. Corrosion of magnesium. Int. Mater. Rev. 1993, 38, 138-153. [CrossRef]

27. Antunes, R.A.; de Oliveira, M.C. Corrosion fatigue of biomedical metallic alloys: Mechanisms and mitigation. Acta Biomater. 2012, 8, 937-962. [CrossRef]

28. Gu, X.N.; Zhou, W.R.; Zheng, Y.F.; Cheng, Y.; Wei, S.C.; Zhong, S.P.; Xi, T.F.; Chen, L.J. Corrosion fatigue behaviors of two biomedical Mg alloys-AZ91D and WE43-In simulated body fluid. Acta Biomater. 2010, 6, 4605-4613. [CrossRef]

29. Bauer, M.; Schilling, T.; Weidling, M.; Hartung, D.; Biskup, C.; Wriggers, P.; Wacker, F.; Bach, F.W.; Haverich, A.; Hassel, T. Geometric adaption of biodegradable magnesium alloy scaffolds to stabilise biological myocardial grafts. Part I. J. Mater. Sci. Mater. Med. 2014, 25, 909-916. [CrossRef]

30. Witte, F.; Kaese, V.; Haferkamp, H.; Switzer, E.; Meyer-Lindenberg, A.; Wirth, C.J.; Windhagen, H. In vivo corrosion of four magnesium alloys and the associated bone response. Biomaterials 2005, 26, 3557-3563. [CrossRef] 
31. Kuhlmann, J.; Bartsch, I.; Willbold, E.; Schuchardt, S.; Holz, O.; Hort, N.; Hoche, D.; Heineman, W.R.; Witte, F. Fast escape of hydrogen from gas cavities around corroding magnesium implants. Acta Biomater. 2012, 9, 8714-8721. [CrossRef]

32. Seitz, J.M.; Collier, K.; Wulf, E.; Bormann, D.; Bach, F.W. Comparison of the corrosion behavior of coated and uncoated magnesium alloys in an in vitro corrosion environment. Adv. Eng. Mater. 2011, 13, B313-B323. [CrossRef]

33. Von der Hoeh, N.; Rechenberg von, B.; Bormann, D.; Lucas, A.; Meyer-Lindenberg, A. Influence of different surface machining treatments of resorbable magnesium alloy implants on degradation-EDX-analysis and histology results. Mat. Wiss. Werkstofftechnik 2009, 40, 88-93. [CrossRef]

34. Witte, F.; Fischer, J.; Nellesen, J.; Crostack, H.A.; Kaese, V.; Pisch, A.; Beckmann, F.; Windhagen, H. In vitro and in vivo corrosion measurements of magnesium alloys. Biomaterials 2006, 27, 1013-1018. [CrossRef] [PubMed]

35. Zheng, Y.F.; Gu, X.N.; Witte, F. Biodegradable metals. Mater. Sci. Eng. R 2014, 77, 1-34. [CrossRef]

36. Pardo, A.; Merino, M.C.; Coy, A.E.; Arrabal, R.; Viejo, F.; Matykina, E. Corrosion behaviour of magnesium/aluminium alloys in $3.5 \mathrm{wt} \% \mathrm{NaCl}$. Corros. Sci. 2008, 50, 823-834. [CrossRef]

37. Feyerabend, F.; Fischer, J.; Holtz, J.; Witte, F.; Willumeit, R.; Drucker, H.; Vogt, C.; Hort, N. Evaluation of short-term effects of rare earth and other elements used in magnesium alloys on primary cells and cell lines. Acta Biomater. 2010, 6, 1834-1842. [CrossRef] [PubMed]

38. El-Rahman, S.S. Neuropathology of aluminum toxicity in rats (glutamate and GABA impairment). Pharmacol. Res. 2003, 47, 189-194. [CrossRef]

39. Janning, C.; Willbold, E.; Vogt, C.; Nellesen, J.; Meyer-Lindenberg, A.; Windhagen, H.; Thorey, F.; Witte, F. Magnesium hydroxide temporarily enhancing osteoblast activity and decreasing the osteoclast number in peri-implant bone remodelling. Acta Biomater. 2010, 6, 1861-1868. [CrossRef]

(C) 2020 by the authors. Licensee MDPI, Basel, Switzerland. This article is an open access article distributed under the terms and conditions of the Creative Commons Attribution (CC BY) license (http://creativecommons.org/licenses/by/4.0/). 